\title{
Iglesia y política en la transición: Los católicos ante la transición política $^{1}$
}

\author{
Feliciano Montero *
}

\begin{abstract}
RESUMEN ABSTRACT
El enunciado "Iglesia y política en

la transición" es demasiado amplio como para abordarlo en todas sus facetas y dimensiones. Aquí se va a centrar la atención en algunas cuestiones relevantes referidas en concre-

to a la postura politica de los católicos durante la transición.

Previamente se recuerda la posición defendida públicamente por la jerarquía eclesiástica antes y durante el proceso. Lo que habitualmente se define como el "taranconismo". La dis-

cusión sobre la posición política de los católicos se centra en dos cuestiones principales: Jas razones del fracaso politico-electoral de los demócrata-cristianos; $y$ las vicisitudes $y$ diversas expresiones de un cristianis-

The title "Church and Politics during the "Transition" is too wide for analyzing it at all» In this paper we are going to pay attention to some questions about the political position of the catholics during the "Transition" First of all, we remember the position supported by the Ecclesiatical Jerarchy before and during this period that we use to call "taranconismo" The discussion about the political position of the catholics point to two main questions: the reasons for the Cristian-democratic's political-electoral fail; and the vicissitudes and expressions of the left cristian, that influenced in the political transition process, and in the meaning of the Church in front of the "Transición".
\end{abstract}

* Universidad de Alcalá.

1 Con ligeros retoques y alguna actualización bibliográfica ésta fue la ponencia presentada en el coloquio hispano-italiano sobre la transición, celebrado en el Istituto Italiano de Cultura en Madrid, en 1994. 
mo de izquierdas, relativamente influyente en el proceso de transición política, y en la propia definición de la Iglesia ante la transición.

PALABRAS CLAVE Iglesia, catolicismo, partidos católicos, transición.
KEY WORDS

Church, catholicism, catholics pary, transition.

El enunciado "Iglesia y política en la transición" es demasiado amplio como para abordarlo en todas sus facetas y dimensiones en un artículo, aparte de que, como ya señalé en un estado de la cuestión sobre el tema, apenas ha sido abordado aún por la investigación, salvo en lo que se refiere al análisis del discurso público, o al análisis del voto católico y su relación con el proceso de secularización ${ }^{2}$. Por ello voy a centrar mi atención aquí en algunas cuestiones relevantes referidas en concreto a la postura política de los católicos durante la transición, partiendo, previamente, de un recordatorio de la postura defendida públicamente por la jerarquía eclesiástica antes y durante el proceso. Lo que habitualmente se define como el "taranconismo", y que remite a otra cuestión más general, que aqui no se abordará, sobre la existencia de una estrategia de la Iglesia (en el Vaticano y en la Conferencia episcopal española) para la transición política. La discusión sobre la posición política de los católicos la centraré en dos cuestiones principales: el drama de los demócratacristianos incapaces de consolidarse como fuerza política autónoma con suficiente respaldo; $y$, en segundo lugar, las vicisitudes y diversas expresiones de un cristianismo de izquierdas, relativamente influyente en el proceso de transición política, y en la propia definición del conjunto de la Iglesia ante la transición. Cronológicamente el análisis se centra en la etapa de la transición política propiamente dicha, 1975-78, aunque será necesario, y especialmente tratándose de la Iglesia, referirnos a unos antecedentes decisivos, los años sesenta y el impacto del concilio Vaticano II, si se quiere entender mínimamente la posición de los católicos españoles durante la transición.

La primera pregunta sobre la posición de la Iglesia-Jerarquía ante la transición, podría formularse así: ¿Tuvo la Iglesia como institución, desde

F. MONTERo, «La Iglesia y la transición» en M. Redero San Román (ed.). La transición a la democracia en España, “Ayer», 15, 1994, pp. 223-241; para referencias bibliográficas más concretas remito a este artículo. 
el Vaticano y desde la jerarquía española una estrategia para la transición? Es obvio que se trata de una pregunta casi imposible de responder más que a un cierto nivel, el que se desprende de las posiciones públicas, individuales y colectivas de los obispos, en entrevistas, conferencias, pastorales ${ }^{3}$; ante la inaccesibilidad a una documentación y unas fuentes "muy reservadas". De todas formas puede ser interesante aludir a la opinión de algunas personas tan cualificadas como la del embajador Antonio Garrigues, quien desde el Vaticano del Concilio y del postconcilio observó en primera fila la especial atención de Pablo VI a la evolución del tardofranquismo, y los sucesivos intentos de negociación de un nuevo concordato. Los informes que el embajador Garrigues enviaba desde el Vaticano son un testimonio excelente para reconstruir la estrategia de la Iglesia ante la transición, durante los últimos años del franquismo ${ }^{4}$. Igualmente significativos son los temores y críticas que las nuevas posiciones de la Iglesia despertaron en sectores gubernamentales que percibieron la politica de Pablo VI, siguiendo los consejos de Benelli, como una operación estratégica amenazadora para la propia consolidación del régimen. "Las maniobras efectuadas por la Secretaría de Estado vaticana a través de monseñor Giovanni Benelli y con la colaboración decidida y a fondo del Nuncio de Su Santidad en España, Luigi Dadaglio empiezan a adquirir sesgos graves para el Estado español». Asi comenzaba un informe confidencial, fechado el 28 de septiembre de 1972, remitido al Gobierno, sobre lo que se interpretaba como toda una operación política, tal como indicaba la conclusión del informe: "la Iglesia vaticana juega con ventaja - y maquiavélicamente- en sus relaciones con el Estado español, cuyas esferas invade en los últimos tiempos, sin estar autorizada por el Concordato ni por ninguna ley moral y ética... Según parece, se trata de conseguir que Franco adopte alguna medida de fuerza contra el Nuncio - solicitando su expuisión, por ejemplo como "persona non grata»-, para provocar otras subsiguientes que llevarian aparejada «ipso facto», la excomunión del Jefe del Estado español, como se hizo ya anteriormente en Argentina con

L. Martin Descalzo, Tarancón, el cardenal del cambio, Barcelona, 1982, Planeta; M. Mérida. Entrevista con la Iglesia, Barcelona, 1981, Planeta; J. Iribarren (ed.) Documentos de la Conferencia episcopal española, 1965-1983, Madrid, 1992, BAC; Tarancón, Jubany, González Iglesia y política en la España de hoy, Salamanca, 1980. Sígueme; un completo banco de referencias en J.I. Calleja, Discurso eclesial para la transición democrática, 1975-1982. Vitoria, 1988, ed. Eset.,

4 Extractos amplios de los informes de Garrigues los publica L. SuAREZ, en Franco y su tiempo, vol. VII. En un testimonio verbal, en el contexto de un coloquio sobre "Pablo VI y España", celebrado en Madrid en mayo 1994, Antonio Garrigues reconocía la preocupación del Vaticano y de Pablo VI por una salida pacifica del Régimen de Franco, y el peso de su experiencia italiana y vaticana, a la caída del fascismo, en la percepción del caso español. Pablo VI y España, Brescia, 1996, publ. del Istituto Paolo VI. 
Perón, el cual poco después era destituído por las Fuerzas Armadas bonaerenses". Independientemente del impacto que este $u$ otros informes similares pudieron tener en la política del Gobierno, el clima de mútuo recelo y cierta hostilidad que revela, lo confirman tanto las memorias de López Rodó como las "confesiones" de Tarancón que con todo pormenor cuenta las tensiones provocadas por la celebración de la Asamblea Conjunta y la aprobación vaticana de las conclusiones ${ }^{5}$.

Sería interesante tambien analizar comparativamente con el caso español el papel de la Iglesia italiana en la transición democrática de la inmediata postguerra, pero exigiría un estudio específico que no abordo aquí. Sólo quisiera hacer una breve alusión a los contextos eclesiales tan diferentes en que se producen ambas transiciones, y a algun eco del ejemplo italiano durante la transición española. En primer lugar hay que decir que la referencia del catolicismo español a la experiencia italiana, a su vez directamente condicionada por las directrices vaticanas, es recurrente. Por citar un sólo ejemplo significativo, los sucesivos Estatutos de ACE miraron siempre el modelo italiano $(1932,1939,1946,1959)$... Ahora bien, cualquier posible comparación entre la postura de los católicos italianos y españoles en los respectivos procesos de transición (1943-46; 1973-77), tiene que tener en cuenta como primer y principal factor diferenciador los distintos «tiempos" de la Iglesia Católica:

- La Iglesia de Pío XII, durante la postguerra, tras la experiencia fascista, y en el clima anticomunista de la "guerra fría", se alza con una alternativa propia, "tercera vía", en el plano ideologico la Doctrina Social de la Iglesia, y en el político la democracia cristiana. El «Movimiento por un mundo mejor" de Lombardi, a partir de 1952 hasta la muerte de Pío XII, es la plasmación, en el terreno propiamente religioso-pastoral de esa alternativa social y política anticomunista y anticapitalista. Los ecos de esa alternativa, muy fuertes todavia al inicio del pontificado de Juan XXIII, van a quedar rápida y bruscamente superados por la teología de lo temporal del Vaticano II.

- La Iglesia del Vaticano II asume el cuestionamiento de esa "tercera vía». La "Ecclesiam Suam», de especial impacto en la conciencia católica española, abre un diálogo profundo con la modernidad, que implica una

El informe anónimo en AGA, Cultura, Fondo Gabinete de Enlace, caja 552, 00200; L. LóPEZ Rodó, El principio del fin. Memorias. Plaza Janés, 1992; V.E. Tarancón, "Mis recuerdos de Pablo VI» en Pablo VI y España, op. cit. pp. 242-262; y Confesiones, Madrid, 1996, ed. PPC. Una crítica virulenta al «taranconismo" en B. Piñar, Mi réplica al cardenal Tarancón, Madrid, 1998, ed. F.N. Sobre la Asamblea Conjunta, vid. Gerardo FeRnÁndez FERNÁNDEZ, Religión y poder. Transición en la lglesia española. León, 1999, Edilesa, basado en la tesis doctoral en Antropologia leida en la UNED. 
cierta renuncia o puesta entre paréntesis de la propia alternativa. La "Octogesima Adveniens" de Pablo VI contempla esa crisis de la DSI, y sanciona la legitimidad de un cierto diálogo y colaboración con otras ideologias y militantes, o al menos así fue percibida y "recibida" por la conciencia católica española ${ }^{6}$. Ese clima de pluralismo y cuestionamiento de la "tercera vía" es el vigente en la mentalidad católica española, tanto de parte de la Jerarquía como de buena parte del clero, y, sobre todo, de la militancia seglar en el tiempo de la pre-transición y de la transición.

- En el tiempo de la transición política española hay señales del eco y la influencia de la circunstancia italiana en el proceso español que merecerían una análisis detenido. En plena etapa pre-transicional, en la primavera de 1976, aún durante el gobierno Arias, llega a los medios católicos españoles el debate sobre el "compromiso histórico" y la condena vaticana a los candidatos católicos integrados en el partido comunista italiano. Un medio católico tan influyente y representativo como "Vida Nueva" acoge con respeto pero con matices esa condena, evitando la aplicación mimética de las recomendaciones y condenas vaticanas a una situación como la española, que en ese momento se esfuerza en plataformas de coordinación por una salida democrática, y rechaza mayoritariamente la vía de un partido confesional. En el "Boletín de la HOAC" se recoge tambien con inquietud la condena de una colaboración que los militantes obreros cristianos practican hace tiempo, y el apoyo vaticano a un partido confesional. Un año después, la revista "Iglesia Viva" publicaba un significativo comentario sobre la experiencia italiana de la relación Iglesia-democracia cristiana, en la perspectiva histórica, con la intención explícita de que pueda ser una lección para España. El artículo en cuestión venía a ser una llamada de atención sobre la tentación de esa opción política, en línea con lo que venía propugnando la revista?.

E. NASARRE en "La recepción de la enseñanza de Pablo VI en materia social y política», en Pablo VI y España, op. cit. pp.170-188, subraya este clima postconciliar en el catolicismo español. Un ejemplo del eco de "Ecclesiam Suam" en las V Jornadas de la ACE, mayo, 1964, La Acción Católica en una Iglesia abierta al mundo, Madrid, 1964 sobre el diálogo generacional, en la sociedad, en la Iglesia y en la propia AC.

Luciano MART IN, "Iglesia y politica en Italia" Iglesia Viva, 67-68, enero-abril,1977, pp. 161-175; dentro de un número monográfico titulado "lglesia y poder en el neocapitalismo". El eco en el Boletín de la HOAC en "El Papa y el comunismo en Italia", comentario dentro de la sección "La Iglesia en tres columnas", Boletin HOAC, 691,15-VII-1976; "Italia entre Gransci y Pablo VI", Boletin HOAC, 689, 15VI-1976; En Vida Nueva, "Nuestro católico derecho a disentir", editorial del 22-V-76, se comenta críticamente la declaración de los obispos italianos: "la vieja lucha política de izquierdas y derechas, identificando a éstas con los grupos católicos, resurge de una forma que creemos honradamente desfasada y peligrosa"; el 26-VI, la revista recoge las declaraciones de Ruiz Gimenez a la revista Guadiana, respetando pero lamentando la postura del Papa, y pidiendo no se extrapolen a la politica española. 


\section{LA IGLESIA PREPARA Y ANTICIPA LA TRANSICIÓN ${ }^{8}$}

La posición de la Iglesia española y de los católicos durante la transición sólo se puede entender en un contexto cronológico más amplio que el tiempo corto de 1975 al 78 , pues está marcada por una continuidad fundamental con la posición adoptada en los últimos años del franquismo. El progresivo "despegue» de la Iglesia respecto del régimen franquista, que se inicia en las "bases" desde el inicio de los años sesenta, y culmina en la Asamblea conjunta de obispos y sacerdotes de 1971, habia preparado el camino de la transición política. Por tanto, la cuestión aquí planteada de la posición de la Iglesia y de los católicos ante la transición vale la pena considerarla en sus antecedentes:

- En un primer momento, al final de la 2. a guerra mundial. En colaboración y relativo acuerdo/desacuerdo con los partidarios de una alternativa monárquica, los católicos "colaboracionistas" intentan una evolución desde dentro, en una dirección aún no liberal. Tusell ${ }^{9}$ subraya la discusión que esta opción de Pla i Deniel-Herrera Oria-Martín Artajo provoca en el seno de la ACNP y ei distanciamiento o rupturas personales que se producen en función de las distintas posiciones tomadas por unos (Artajo, Ruiz Gimenez) y otros (Gil Robles, De Luis, Gimenez Fernandez). Ruptura y tensiones que son la clave de posteriores distancias y divisiones dentro de los demócrata-cristianos.

En ese mismo contexto, el nacimiento de las especializaciones obreras dentro de la Acción Católica, en 1947, y en concreto de la HOAC, está vinculado a ese mismo proyecto de transición moderada. Ante la eventualidad de esa evolución sería bueno preparar la base sindical de un futuro partido democrata-cristiano. Los militantes de la HOAC atribuyeron estos objetivos políticos a algunos de los fundadores y colaboradores más estrechos (Rodríguez Soler); y explican ciertas tensiones y crisis posteriores de la HOAC con la Jerarquía, como los ceses de Rovirosa (1958) y Malagón (1963), por la disidencia respecto de esa «politización" demócrata-cristiana de la HOAC. ${ }^{10}$

\footnotetext{
8 Una visión de conjunto en “Los católicos en la lucha por la democracia», $X X$ siglos, 16. 1993, número monográfico, a partir de un encuentro en "el Escorial», noviembre 92, sobre la contribución de los cristianos desde los Movimientos.

9 J. TUSELt, Franco y los católicos, Madrid, 1984

10 Documentos internos de la HOAC, en forma de balances o revisiones históricas, expresan esta percepción. Vid. Archivo HOAC, caja 227. Vid. tambien, B. LOPEZ GARciA, Aproximación a la historia de la HOAC, 1946-1981, Madrid, 1995, ed. HOAC; y A. Murcia, Obreros y obispos durante el franquismo, 1995, Ed. HOAC,
} 
- En un segundo momento, en los sesenta, coincidiendo de un lado, con los proyectos institucionalizadores del régimen, y de otro con el impacto del Vaticano II, en el seno de la Iglesia y del catolicismo español se produce una fuerte división interna en torno a la legitimación o no de la "democracia orgánica». Las encíclicas sociales de Juan XXIII y Pablo VI y los documentos conciliares hacen crecer las expectativas de un sector reformista, partidario de un cambio democrático, y colaboracionista con instancias politicas clandestinas (diálogo cristiano-marxista). Frente a esta posición rupturista con el régimen, dispuesto a colaborar con la oposición, se situan los partidarios de continuar con el colaboracionismo más o menos crítico, como el cardenal Herrera y los Propagandistas. Es tambien la posición del sector mayoritario del episcopado en la primera etapa de la Conferencia Episcopal durante la secretaría de Guerra Campos; la que sanciona favorablemente el referéndum de 1966 sobre la Ley Orgánica.

La crisis de la ACE de 1966-68 tiene varias "lecturas" posibles. Fundamentalmente ha de ser considerada desde una doble perspectiva: en primer lugar como conflicto disciplinario con la Jerarquía episcopal, pero tambien como síntoma de una crisis de identidad, que por esas mismas fechas, y un poco antes, se había manifestado en otras latitudes católicas. Pero desde la perspectiva que aquí nos interesa, la crisis de la ACE no es más que la expresión culminante de esa división entre rupturistas y colaboracionistas a la que nos referíamos.

La inviabilidad, en esos años sesenta, de una transición pacífica, análoga a la que se producirá una década despues, imposibilita la consolidación y configuración de una alternativa política demócrata-cristiana, con importante base de militancia católica (AC, Congregaciones, etc...). Se produce entonces, lo que algunos autores llaman, la "diáspora»: la desintegración de la propia democracia cristiana en varias opciones minoritarias, el ingreso de militantes católicos en partidos y sindicatos socialistas y marxistas.

Mientras tanto en la cúpula de la Iglesia se producía un fuerte debate sobre la solución más acertada; debate que llega a concretarse en la existencia de dos líneas en la secretaría de Estado: la posición que representaba Benelli (coincidente con la línea de los Movimientos especializados de $\mathrm{AC}$ ) muy crítica con el régimen, y la de Casaroli, más proclive a llegar a nuevos acuerdos concordatarios con los últimos gobiernos de Franco (proyectos de López Bravo y de Lopez Rodó) ${ }^{11}$.

"Una visión muy detallada y muy bien informada del impacto de las vicisitudes vaticanas sobre el catolicismo y la política española en los sesenta en J.M. Piñol, La transición democrática de la Iglesia católica española, 1999, Madrid, Trotta, 
- El comienzo de los 70 marca el inicio de una nueva etapa, marcada por la renovación del episcopado, el cambio de posición de la Iglesia oficial, ahora abiertamente partidaria de la transición democrática (Asamblea conjunta, "Iglesia y Comunidad Política», "taranconismo"), y, por ello, fuertemente enfrentada a las posiciones gubernamentales más extremas: las tensiones por la negociación de la revisión del concordato son una expresión significativa de esta situación. (las dos líneas en la Secretaría de Estado: Benelli, Casaroli). Progresivamente las demandas de la Jerarquía van siendo cada vez más claramente pro-democráticas: documentos sobre "Iglesia y comunidad política", sobre "El Apostolado Seglar", invitación a la reconciliación. La Iglesia presta su cobertura a las acciones reivindicativas de la oposición sindical y política: locales parroquiales, retiros, reuniones, círculos de estudio, y las publicaciones internas de los Movimientos. Los enfrentamientos con el gobierno son constantes. El más llamativo y representativo de este conflicto es el tan citado caso Añoveros.

La militancia seglar católica, despues de la crisis del 66-68, se radicaliza política (opciones marxistas) y eclesialmente (lucha de Iglesia): nacen las Comunidades Cristianas Populares (nueva iglesia popular frente a la iglesia institucional); se constituye "Cristianos por el socialismo" (CPS), en 1973; en el seno de las Vanguardias Obreras (VVOO) nace la AST y luego la Organización Revolucionaria de Trabajadores (ORT). Todo este auge del catolicismo progresista en España hay que entenderlo en el contexto de una particular recepción del Vaticano II, especialmente de la doctrina político-social de la "Gaudium et Spes», que han analizado ajustadamente varios analistas ${ }^{12}$.

\section{LA JERARQUIA ECLESIÁSTICA ANTE LA TRANSICIÓN}

El punto de partida y el marco para analizar la postura política de los católicos españoles durante la transición, ha de ser un breve recordatorio del discurso público de la Jerarquía, máxime cuando algunos siguen considerando el "taranconismo" como factor explicativo básico del fracaso de la Democracia Cristiana y de la importancia relativa del catolicismo de izquierda.

La postura de la Iglesia jerárquica en la primera fase de la transición (especialmente hasta las elecciones de junio de 1977), a la vista de los documentos públicos colectivos de la Conferencia Episcopal (en asamblea Plenaria o la Comisión Permanente), fue de apoyo claro al

\footnotetext{
12 Entre otros, la ponencia citada supra de Nasarre en el coloquio "Pablo VI y España"; $O$. González de Cardedal, España por pensar, Salamanca, 1985 2. ${ }^{\text {e ed., }}$
} 
proceso de reforma democrática, en clave de reconciliación (petición de indulto, condena de la violencia terrorista). Esta posición estaba en línea de continuidad con la propugnada por la propia Conferencia Episcopal en los últimos años del franquismo, especialmente a partir del documento "Iglesia y comunidad Política» (1973). Esta postura de la jerarquía eclesiástica, que era la expresión de la llamada línea Tarancón, se puede resumir en las siguientes líneas directrices: apoyo y legitimación clara del proceso de reforma democrática en clave de reconciliación, y de los valores democráticos implicados; incitación a la participación y al compromiso politico, plural y libre, de los católicos; y rechazo explícito de cualquier proyecto confesional político o sindical, en nombre de la "autonomia" de las cosas temporales, y de la independencia de la Iglesia respecto a cualquier opción política ${ }^{13}$. Esta posición de la jerarquía eclesiástica española venía inducida por la reflexión del conjunto de la Iglesia, a partir del Vaticano II, sostenida por Pablo VI durante su pontificado, y por la propia reflexión histórica, autocrítica, sobre los efectos negativos de la beligerancia católica contra la 2. ${ }^{a}$ República, y el posterior «maridaje» con el Estado confesional nacional-católico ${ }^{14}$.

A partir de las elecciones de junio del 77 , ya en el proceso de debate de la Constitución, la posición de la Jerarquia, sin dejar de apoyar el proceso democrático, comienza a ser más defensiva y critica, frente a los pronunciamientos laicistas de fuerza políticas que habian validado su implantación social en las elecciones: la consideración matizada de la

\footnotetext{
13 Entre los diversos documentos de la Conferencia Episcopal los que mejor expresan la posición de la Jerarquia en la primera fase de la transición son los siguientes: el de la Comisión Episcopal de Apostolado social, "Orientaciones cristianas sobre participación política y social", de julio de 1976, y el comunicado final de la 62. ${ }^{a}$ Permanente, en abril del 77 "Ante las proximas elecciones" (este comunicado fue acompañado de la edición masiva de "trípticos" explicativos sobre la posición de la Iglesia. La definición de criterios o valores que el elector católico tenía que tener en cuenta, entre los distintos programas politicos, a la hora discernir las opciones favorables o rechazables desde un punto de vista catolico, dejaba un margen relativamente amplio a la pluralidad de opciones

Ciertamente la posición del conjunto episcopal ante las elecciones era lógicamente más genérica que la contenida en las orientaciones de los secretariados sociales de las diócesis vascas, mucho más explícitas en el apoyo inequivoco al cambio democrático, en un sentido claramente constituyente, de acuerdo con el criterio de los partidos democraticos históricos a que la "reforma" no implicara la ruptura, y con fuerte contenido "social", Secretariados Sociales de Pamplona, Bilbao, San Sebastian y Vitoria: "Ante las próximas elecciones", Iglesia Viva, 67-68, pp.153-159,

14 La revisión histórica autocrítica era reciproca. Los programas religiosos de los partidos laicistas y la política religiosa de los distintos gobiernos democraticos, tanto de la UCD como del PSOE, va a estar marcada por un cuidado especial en impedir la reproducción de los "errores" cometidos durante la II República.
} 
aconfesionalidad del Estado, que no excluyera un reconocimiento sociológico del peso mayoritario del catolicismo en la sociedad española; la preocupación por la regulación del matrimonio civil y del divorcio, y de la libertad de enseñanza, son los temas del debate constitucional, que por un momento parecen reproducir, aunque muy atenuadamente, los viejos "fantasmas" del clericalismo-anticlericalismo que todos, por otra parte siguen interesados en auyentar ${ }^{15}$.

La postura de la Jerarquía ante la Constitución era en conjunto favorable, aunque incluía una crítica moderada, y ciertas reservas sobre el desarrollo legislativo posterior de algunos de los principios constitucionales, acorde con los pactos conseguidos en el texto constitucional, y los acuerdos negociados al más alto nivel, firmados pocos días después del referéndum constitucional No hay que olvidar que mientras en el Parlamento y la "comisión de notables" se pacta y discute la Constitución, a otro nivel una comisión eclesial-gubernamental negocia los acuerdos jurídicos Iglesia-Estado que desarrollarían el primer acuerdo de julio del 76 , y sustituirian el concordato del 53.

Aprobada la constitución, consolidada la transición política propiamente dicha, la apertura del debate político sobre el desarrollo legislativo de los principios constitucionales (especialmente la libertad de enseñanza) coloca a la Jerarquía en una posición cada vez más crítica y combativa, que la separa progresivamente de los sectores católicos vinculados a posiciones más seculares y socialistas ${ }^{16}$.

La supuesta débil postura de la Conferencia Episcopal ante el golpe del 23 de febrero de 1981 ha sido objeto de algunas especulaciones con escaso fundamento. La línea de apoyo explícito y rotundo a la transición política desde los inicios, no habia sido rectificada por algunos desacuerdos y críticas puntuales mencionadas. La verdadera confrontación de la Jerarquía con los políticos y gobiernos de la transición se va a producir con los gobiernos socialistas, a partir de octubre del 82, en relación con los proyectos se regulación del aborto, y la nueva regulación de la libertad de

15 De esta epoca, de debate constituyente, son el documento de la Plenaria (de noviembre del 77) sobre "Los valores morales y religiosos ante la Constitución", y el de la Permanente, de julio del 78, sobre "Posiciones del Episcopado sobre educación y enseñanza", y la nota de la misma Permanente, de septiembre del 78 , sobre “El referéndum constitucional», parcialmente contestada por la pastoral del primado Gonzalez Martin y ocho obispos más, mucho más critica con la Constitución.

16 El documento de la 31. Plenaria (julio 79) sobre "Familia y Matrimonio", y los de la 32." Plenaria (noviembre 79) sobre el divorcio civil, y sobre la enseñanza marca la posición del conjunto de los obispos. El recurrente tema del divorcio es retomado de nuevo por la Permanente en tebrero del 81 y junio del 81 al hilo de los sucesivos proyectos y debates promovidos por los go. biernos de la UCD (ministro F. Ordoñez). 
Iglesia y politica en la transición: Los católicos ante la transición política

enseñanza (financiación de los centros privados). Ahora la Jerarquía manifiesta su intención de cerrar una etapa de apoyo casi incondicional y de neutralidad, e iniciar otra de afirmación independiente y confrontada ${ }^{17}$.

\section{EL CATOLICISMO POLITICO DURANTE LA TRANSICIÓN. EL FRACASO DE LA DEMOCRACIA CRISTIANA}

¿Por qué fracasó la previsión de Linz de una alternativa democrata-cristiana? Esta es la respuesta del propio Linz a la pregunta que le formulaba Ignacio Sotelo en 1991. "Cuando yo escribí en Palo Alto, creo que en 1963, el trabajo sobre el sistema de partidos políticos que está publicado en el libro editado por Lipset y Rokkan, hice unas consideraciones de cómo votarian los aspañoles si votasen como los italianos, es decir, trasladando la conducta electoral de los italianos a la estructura demográfica española. Con este criterio los españoles salian un poco más de izquierda que los italianos. Este análisis estaba basado en la alternativa que representaba un centro derecha que naturalmente era la democracia cristiana, lo cual no quiere decir que en 1976 pensara que la cristianodemocracia pudiera ir a ninguna parte. Ahora bien, si ves la base sociológica de lo que fue la UCD es exactamente la de la democracia cristiana, tal vez con la falta del elemento obrero, no hay un sindicato cristiano. Suárez ocupó el sitio que le dejó una democracia cristiana, que queria jugar a la izquierda y con una iglesia postconciliar empeñada en que no hubiera democracia cristiana. Mi pronóstico es anterior al concilio. Con la crisis de la Acción Católica, con la JOC y la HOAC siendo semillero de cosas distintas, y dada la incapacidad de Ruiz Giménez de articular una posición en el centro derecha y el fracaso lógico de Gil Robles, obviamente no pudo hacer una democracia cristiana, pero hay un equivalente funcional, que es la UCD, y desde este punto de vista las predicciones electorales que hice en ese estudio no estaban del todo erradas". Al margen de la validez exculpatoria de sus previsiones de $1963^{18}$, la respuesta aporta claves interesantes

\footnotetext{
1) Una primera valoración crítica de este "giro" de la postura de la lglesia, del apoyo a la critica, en R. DiAz SALAZAR, Iglesia, dictadura y democracia, Madrid, 1981, ed. HOAC; especialmente cap. VII “El malestar de la Iglesia» pp. 375 y ss.; tambien S. Giner y S. Sarasa «Religión y modernidad en España” en Religión y sociedad en España. CIS, pp.51-87. Un balance reciente de uno de los protagonistas, Fernando Sebastian Aguilar, «Iglesia y Democracial. La aportación de la Conferencia Episcopal Española», XX Siglos, 39, 1999,1, pp. 89-108.

"LINZ. Entrevista con Ignacio Sotelo", Claves, 16, 1991. Parece que en otras previsiones elaboradas por encargo de la "Federación Popular Democrática" de Gil Robles, en vísperas de las elecciones de junio del 77 , tambien se equivocó rotundamente (del $16 \%$ a poco más del $1 \%$ del electorado, lo que dejó a Gil Robles y a Ruiz Jiménez sin escaño).
} 
para comprender el fracaso de la democracia cristiana y el peso del voto y la militancia católica en los partidos de izquierda.

El mejor estudio sobre la UCD coincide básicamente con la apreciación "a posteriori» de Linz sobre el fracaso de su previsión: «Para entender el fracaso de un partido demócrata-cristiano en España - dice Carlos Hunneus en su libro- examinamos dos aspectos que Linz no pudo prever o no evaluó suficientemente. En primer lugar, los fundamentos político-culturales para el surgimiento de un partido democratacristiano, cuestión que nos remite a la "memoria histórica" y al carácter de la Iglesia católica en España; en segundo lugar, la fragmentación de los partidos demócratacristianos durante el franquismo, las diferencias personales entre sus principales dirigentes y sus errores políticos cometidos en los momentos claves del cambio de régimen ${ }^{19}$.

Según la revisión autocrítica de los propios demócrata-cristianos en un encuentro celebrado en "El Escorial» en $1994^{20}$, éstas serian algunas de las claves de su fracaso: las divisiones internas; la dificultad y ambiguedad en la presentación como partido confesional (de IDC a ID); la falta de base social obrera y sindical, correspondiente a una tradicional escasa sensibilidad social del catolicismo español; el contexto eclesial europeo desde el Vaticano II, el debate electoral italiano de abril del 76 sobre "el compromiso histórico", y la pertinencia de la militancia y el voto católico a las candidaturas comunistas; la falta de apoyo explícito por parte de la Jerarquia, con la expresa decisión de Tarancón de no apoyar una opción de este tipo. Repasemos algunos de estos factores explicativos.

Las divisiones internas en el seno de la Democracia Cristiana eran demasiadas y en algun caso demasiado profundas. Una sensibilidad distinta separaba a los colaboracionistas con el franquismo de los que habian militado en la oposición. $Y$ dentro de estos últimos, a la generación del exilio (Gil Robles) y la automarginación (Giménez Fernández), de la nueva generación de los años 60, vinculada a Ruiz Gimenez y "Cuadernos para el diálogo", a medio camino entre una posición demócrata-cristiana de izquierdas, y el socialismo democrático.

La fuente de la división no eran pues sólo los personalismos. Pero, según la percepción a posteriori de algunos hubo algún exceso de «pu-

\footnotetext{
19 C. Hunneus, La Unión de Centro Democrático y la transición a la democracia en España, Madrid, 1985, ed. CIS, p. 176.

20 Encuentro celebrado en noviembre de 1994; las referencias citadas están tomadas no literalmente de diversas intervenciones en el citado coloquio. vid. "Los demócrata cristianos en la transición española", en XX Siglos, 26, 1995.
} 
rismo" que impidió la fusión entre las distintas familias, especialmente entre los demócrata-cristianos franquistas y los antifranquistas ${ }^{21 .}$

La decisión de Tarancón, confirmada plenamente por testimonios orales, todavía hoy es valorada polémicamente por los principales líderes de aquel tiempo, como factor coadyuvante en el fracaso de la D.C. en las elecciones de 1977: Para algunos la actitud de la Jerarquía fue contraproducente; "primero nos dejaron sin bases, tras la crisis de la ACE de los años 60 , y luego nos dejaron sin nombre..." Aunque reconocen que, en general, toda la coyuntura histórica no podía ser menos favorable. Otros, más allá de la postura concreta de Tarancón, critican amargamente la falta de visión de la Iglesia, guiada por el "corto plazo", condicionada siempre desde la desamortización del siglo xıx, por la precariedad financiera. Otros, en cambio, consideran correcta, eclesial y políticamente, la posición de Tarancón y de los obispos. En esta misma línea, Alzaga, en un contexto diferente, más eclesiástico ${ }^{22}$, subrayó que la neutralidad de Tarancón no fue factor decisivo en el fracaso electoral. La posición aconfesional de los obispos sería compartida por los propio demócrata-cristianos, conscientes desde el Vaticano II, de la inviabilidad de un partido confesional.

En una línea semejante, Eugenio Nasarre, estudioso, además de protagonista, del catolicismo postconciliar, situa los límites de la opción demócrata-cristiana durante la transición, en el contexto mental del catolicismo español postconciliar, que recibe el Vaticano II y las encíclicas de Pablo VI en unas determinadas claves. Señala, como ejemplo, la específica y peculiar recepción de la "Octogesima Adveniens" como deslegitimadora de las opciones confesionales, tanto doctrinales (DSI) como sindicales o partidarias. Para Nasarre dicha recepción e interpretación desbordaba y tergiversaba, en alguna medida, el significado real de los documentos conciliares y pontificios ${ }^{23}$.

En suma, la posición neutralista y explícitamente aconfesional defendida por Tarancón ¿ fue una posición oportunista o realista? Por una parte Tarancón se apoyaba sinceramente en una convicción largamente madurada en la reflexión (la teologia del Vaticano II), y en la experiencia

${ }^{21}$ En el n. ${ }^{\circ}$ de XX Siglos, 26, 1995, vid. especialmente los articulos de Iñigo Cavero, J.A. Ortega diaz-Ambrona, O. Alzaga, y E. Nasarre. Además la tesis de D. Barba Prieto, La Democracia Cristiana durante el franquismo., Uned, 2000, narra los recelos internos entre los diversos lideres.,

22 Óscar Alzaga, Testimonio, en Pablo VI y España, op. cit. pp. 197; La explicación del propio Tarancón al respecto en J.L. Martin Descalzo, Tarancón el cardenal del cambio, op. cit. y en Tarancón, Contesiones.

23 E. NasarRe, “La recepción de la enseñanza de Pablo VI..» op.cit., pp. 170-188. 
histórica (los efectos de la "cruzada» en el catolicismo español). Por otra se ajustaba especialmente bien a la nueva realidad sociológica del catolicismo español, tal como después han reflejado bien los numerosos estudios de opinión y los analisis electorales del voto católico. Los sondeos del CIS, los estudios de Linz, J.R. Montero y Díaz Salazar, el capítulo correspondiente del informe Foessa sobre el cambio social en España, o los más recientes de González Anleo y Blasco ${ }^{24}$ coinciden con ligeras variantes en la descripción del proceso secularizador y en la importancia de la opinión de izquierda entre los católicos, especialmente en la franja de los poco practicantes. La realidad social plural que ponen de relieve estos estudios parece avalar «a posteriori» la oportunidad y el realismo de las directrices de Tarancón. Pero no hay que olvidar tampoco los numerosos estudios de sociología religiosa, impulsados desde la Oficina de estadística y sociología religiosa de la Iglesia, especialmente desde los años 60 , que ofrecian tambien una imagen del proceso de secularización como un reto al que una nueva pastoral tenia que responder ${ }^{25}$.

Sin embargo, ya en su momento la posición neutralista y aconfesional defendida por Tarancón fue relativizada. Según comentarios contemporáneos de Aranguren, en julio de 1977, polemizando con Patino, Benzo, Sebastian y Cardenal, el neutralismo de Tarancón habría favorecido claramente a lo que se atreve a llamar, con bastante exageración, el «Zentrum Católico", que representaría el sector de "Propagandistas" integrado en UCD y en los Gobiernos de Suárez. Perjudicando, a su entender, a la izquierda democrata-cristiana de Ruiz Giménez ${ }^{26}$.

24 Una buena selección de estos trabajos en R. DIAZ SALAZAR y S.Giner (eds): Religión y Sociedad en España, Madrid, 1993, ed. CIS. Dentro de este libro el trabajo de Diaz Salazar, "La transición religiosa de los españoles", contiene numerosos cuadros sobre la composición religiosa de los electorados de los partidos o la autoidentificación religiosa de los votantes de cada partido. op. cit. pp. 160-161. J. Gonzalez Anleo, P. Gonzalez Blasco, Religión y sociedad en la España de los años 90 Madrid, 1992, Fundación SM.

25. Entre los diversos estudios el de R. Duocastella, Análisis sociológico del catolicismo español, Barcelona, 1967, Nova Terra, y los del dominico Vázquez, Realidades socio-religiosas de España,. 1967. Madrid, Editora Nacional y La Iglesia española contemporánea (estudios sociológico) Madrid, 1973, Editora Nacional; además diversos estudios diocesanos de sociología religioso-pastorai; las guias de la Iglesia contienen datos sobre estos estudios. Al final del franquismo la situación de la sociologia religiosa en España era estimable, como se ve por las aportaciones españolas a la XIII conferencia internacional de sociología religiosa celebrada en LLoret del Mar en el verano de 1975, vid. Cambio social y religión en España, Barcelona, 1975, Fontanella.

2 Los artículos de Aranguren en "El Pais", "La Iglesia y el poder", 7-VII-77; "El Zentrum católico», 5-VIII-77; “El espacio político-cultural de Izquierda Democrática» 8-IV-78; «la Filosofía la Religión y la Juventud", 21-111-78, están recogidos en el libro La democracia establecida. Una critica intelectual, Madrid, 1979, ed. Taurus. 
Aunque la Jerarquía no condenó expresa y explícitamente las opciones políticas de izquierda, los criterios de delimitación del pluralismo, implícitamente cuestionaban las opciones marxistas. A pesar de que, como demuestran los estudios de opinión y los electorales, una parte relativamente importante de los católicos prácticantes votaban e incluso militaban en esas opciones. Esta ruptura de la tradicional identificación entre el voto católico y las derechas es precisamente una de las novedades históricas principales de la transición.

La escasa sensibilidad social de la Democracia Cristiana, y en concreto su incapacidad para enlazar con una base sindical independiente es reconocida tambien por la mayoría de los demócrata-cristianos como uno de los factores del fracaso. Esta debilidad tradicional en el catolicismo español anterior a la guerra civil (reconocido por la historiografía de los años 70 como el fracaso social del catolicismo español), por un momento pareció rectificarse tras el surgimiento de la Acción Católica obrera, y en especial la HOAC. Desde la perspectiva demócrata-cristiana presente en los fundadores de la HOAC, hombres de AC próximos a la ACNP, como Santiago Corral y Rodríguez Soler, ésta podría ser la base de un futuro sindicato cristiano, imposible, por otra parte, en el marco jurídico de la España franquista. En cambio, desde la perspectiva de los principales ideólogos de la HOAC, Rovirosa y Malagón, la HOAC partía de una radical revisión del catolicismo social y de la Doctrina social de la Iglesia. Una revisión de signo sinceramente obrerista $y$, por tanto anticapitalista, fuertemente antimarxista (y especialmente anticomunista), y próxima en buena medida al anarco-personalismo de la línea de la editorial ZYX. Esa misma inspiración ideológica la hizo pronto recelosa ante cualquier intento de utilización de la HOAC como base sindical de un partido democráta-cristiano (proyecto atribuido por la HOAC a Rodríguez Soler). En todo caso, la prolongación del regimen franquista, y por consiguiente del sindicato único oficial, hacia inviable la constitución de un sindicato obrero cristiano. La propia militancia cristiana en acciones reivindicativas era necesariamente vista como fuente peligrosa de conflictos que ponían en cuestión las armónicas relaciones Iglesia-Estado. Por otra parte el tiempo de esa maduración sindical cristiana (en torno a 1960) coincidió en toda la AC obrera con la crisis del modelo confesional. A partir de ese momento, la única vía era la clandestina y aconfesional.

En ese contexto surgiría de la militancia de la JOC la USO. Si bien el proyecto socio-politico de la HOAC, imposible de cuajar en el interior de un Movimiento de $\mathrm{AC}$, se materializó en un proyecto pedagógico y cultural 
más que sindical: la editorial ZYX. Se trataba de continuar el proyecto de movimiento obrero cristiano de la HOAC, en el marco legal de una sociedad anónima editorial, y fuera de los estrechos límites marcados por la jerarquía eclesiástica.

Paralelamente, dentro de la HOAC fue madurando, en medio de la crisis general de la ACE, un movimiento más aconfesional, más abierto a las influencias y colaboración con las opciones marxistas. Asi que, al llegar la transición (1975) era difícil pensar que la acción católica obrera, superviviente de la crisis, aunque mermada en sus efectivos por las consecuencias generales de la crisis de identidad que afectó a todos los movimientos y militantes, pudiera constituir la base social o sindical de un partido demócrata-cristiano, independientemente de la insensibilidad o falta de sintonia de los propios demócrata-cristianos.

En todo caso, es significativo de esta situación de impotencia el llamamiento de un eclesiástico tan cualificado como Jesús Iribarren, en mayo de 1976, a los hombres de ACNP, dentro de un ciclo de conferencias sobre marxismo-cristianismo. Partidario de plantear la cuestión no en el terreno doctrinal y teórico del diálogo cristiano-marxista (y del movimiento cristianos por el socialismo), sino en el más práctico de las opciones sindicales, se lamentaba de la falta de apoyo a la constitución de un sindicato obrero cristiano, que según el, aún alentaría una mayoría de la HOAC, reacia a entrar en Comisiones Obreras. Iribarren consciente del peso de la posición aconfesional, insistía en la pertinencia de una opción cristiana específica, demandada, según él, por la propia militancia obrera. Independientemente de la adecuación de esta propuesta a la realidad de la HOAC, y de la militancia obrera cristiana (en ese momento mayoritariamente dentro o próxima a posiciones socialistas y marxistas), es muy significativa tanto la posición del conferenciante (que no puede considerarse como mero francotirador), como la del destinatario, los hombres de la ACNP, excesivamente recluidos en posiciones apolíticas. ${ }^{27}$ Pero la verdad es que la propuesta de Iribarren resulta bastante poco verosímil si se atiende a la posición política y sindical defendida por la HOAC en ese tiempo. Una posición revolucionaria y radical, tanto en el terreno político como en el eclesial.

Jesús IRIBARREN, “Unas palabra más sobre Marxismo y Cristianismo", conferencia en la sede de la ACNP en Madrid, el 13-V-1976; publicada en Boletin ACNP, 7, 1976, pp. 24-31. El conferenciante alude a ofrecimientos materiales concretos por parte de los obispos y católicos alemanes para apoyar opciones sindicales y politicas cristianas. 
Explícitamente alejada de cualquier proyecto sindical confesional frente a ciertos proyectos al parecer alentados no por las HOAC sino por las «Hermandades del Trabajo» 28

En suma, más allá de estos factores, la razón principal de fracaso de la Democracia Cristiana era la crisis del modelo confesional de partido. Por una parte la crisis de los partidos y sindicatos confesionales, en el contexto doctrinal de «la autonomía de lo temporal» o la legítima secularización, situaba el principio tradicional del legítimo y conveniente pluralismo político en un terreno mucho más amplio, que incluía y abarcaba tambien las opciones marxistas y en general de «izquierdas».

En vísperas pues de la transición política, era prácticamente inviable una opción política mayoritaria de signo demócrata-cristiano. Si ésta fracasa electoralmente no es sólo por las escisiones y divisiones internas, o por la falta explícita de apoyo por parte de la Jerarquía (posición reiterada de Tarancón), sino por la falta de base "natural» de cuadros y militantes de la AC y de otras organizaciones apostólicas, en buena medida desmanteladas despues de 1968 , y, en todo caso, más próximos a posiciones socialistas que democráta-cristianas. Para una verificación de esta hipótesis general habría que analizar las trayectorias personales de los militantes de la ACE, a partir de 1966-68, la evolución de las organizaciones y Movimientos de $\mathrm{AC}$ que sobrevivieron a la crisis (HOAC, JOC, JEC,etc.), y la de los nuevos Movimientos, "Comunidades de Base", "comunidades cristianas populares", que en parte surgieron como alternativa a los Movimientos.

\section{LA IZQUIERDA CRISTIANA EN ESPAÑA DURANTE LA TRANSICIÓN}

Una de las principales novedades señalada por los politólogos y sociólogos, estudiosos de la transición, es la quiebra de la identificación entre el voto católico y los partidos de derechas. En su lugar aparece un pluralismo muy amplio que va desde las posiciones de la derecha tradicional hasta las marxista-leninistas. Los estudios sociológicos sobre el voto católico en las elecciones de la transición revelan un sector impor-

28 Vid. "No tenemos derecho. No a un sindicato de inspiración cristiana", editorial del Boletin HOAC, 696, 15-IX-1976; Ecclesi”, 1811, 30-X-76, “¿Un sindicato confesional?", se hace eco de la polémica; propugna la libertad de opciones y la pluralidad; recuerda el principio no confesional de "no a la politica cristiana, si a los cristianos en la política". 
tante de votos de izquierda, sin el que no se podría entender la mayoría absoluta socialista de octubre de 1982. La legitimidad de la posición cristiana de izquierdas pasa por un proceso relativamente lento, aunque acelerado desde la segunda mitad de los sesenta. Proceso que tiene que romper con un arraigado anticomunismo y antimarxismo, especialmente anclado en los movimientos apostólicos obreros como la HOAC. El desbloqueo de esa incompatibilidad ideológica y mental se producirá tanto en el terreno doctrinal (diálogo cristiano-marxista), como sobre todo en el de la colaboración práctica en luchas politicas y sindicales concretas. Las declaraciones y los consejos de la Jerarquía, en su afirmación basica del pluralismo legítimo, no llegaron a desaconsejar o desaprobar explícitamente las opciones de izquierda. Lo que supuso que, al margen de la influencia real de esas declaraciones, los católicos españoles durante la transición no tuvieran o hicieran problema de conciencia de su hipotética vinculación a un partido socialista o comunista. Esta orientación del voto católico probablemente se vio influída por una tendencia en cuya configuración contribuyeron las demandas de algunos grupos como "Cristianos por el Socialismo".

Así pues, en vísperas de la transición, el debate político en el interior de la Iglesia y del catolicismo español no era sobre la posibilidad de una opción democráta-cristiana, sino sobre la emergencia de una opción cristiana de izquierdas, ideológicamente compatible con el cristianismo. En las revistas católicas más influyentes de la época el debate candente era sobre el movimiento o corriente "Cristianos por el socialismo" (CPS) ${ }^{29}$. Los estudios de los politólogos y sociólogos sobre la transición se han ocupado del fracaso de una opción demócrata-cristiana (Hunneus) y del "neutralismo" y aconfesionalidad de las directrices episcopales, pero no han dado toda la importancia debida al peso cuantitativo, pero sobre todo cualitativo, de los "Cristianos por el socialismo", cuyas declaraciones contribuyen a explicar tambien la misma posición neutralista de la Iglesia Jerárquica durante la transición, en aras del legítimo pluralismo, y, en definitiva la importancia del voto católico a los partidos de izquierda en las sucesivas elecciones políticas.

No quiero decir, por supuesto, que las demandas de CPS de pluralismo amplísimo y consiguiente respeto a la ciudadanía cristiana de marxistas en

29 Las revista Iglesia Viva dedicó dos números monográficos a "Cristianos por el socialismo" CPS, el 52-53 (julio-octubre 1974) y el 60 (Noviembre 1975); Fomento Social dedicó en abril-junio 1976 , un monográfico, $n .{ }^{\circ} 122$, y otro, el $n .^{\circ} 125$, en enero-marzo de 1977 a la militancia cristiana en los partidos comunistas; Vid. tambien algunos documentos de CPS en A. Fierro y R. Mate, Cristianos por el socialismo, Estella, 1975, Edit. Verbo Divino. 
el interior de la Iglesia, fuera aceptada por la Jerarquía. Más bien se expresaron reticencias, desconfianzas y descalificaciones más o menos veladas. Pero en ninguno de los documentos episcopales principales, con motivo de las elecciones del 77 o del referéndum constitucional del 78 , se encuentra una descalificación expresa y explícita de los partidos de izquierda. De lo que se podría deducir que uno de los objetivos principales de "cristianos por el socialismo", que era esa apertura hacia la izquierda del pluralismo político de los cristianos, se habría conseguido en los procesos electorales.

\section{Las demandas pluralistas de/ CPS}

Según el comunicado fundacional de "Cristianos por el socialismo" (CPS), de Ávila de enero del 73, «nuestra opción por el socialismo...debe ser incluída de una manera explícita en el abanico de posibles opciones políticas que la Iglesia oficial reconoce» $\left(n .{ }^{\circ} 52\right)$. Por eso más adelante afirmaban solemnemente, "proclamamos nuestra carta de ciudadania en el seno de la Iglesia, y no aceptamos ser reducidos a posiciones marginales que nos obligan a actuar en la clandestinidad dentro de esta misma Iglesia" ( $\left.n .^{\circ} 54\right)$. Esta definición de compatibilidad entre cristianismo y opción política socialista quería salir al paso de cualquier intento de apoyo por parte de la Jerarquia a un supuesto proyecto político demócrata-cristiano. CPS denunciaba esta posibilidad, comentando críticamente por "insuficientes y ambiguas" las declaraciones ético-políticas de los obispos, y, señaladamente, el reciente documento sobre "Iglesia y comunidad política". Según CPS «tal ambiguedad está siendo aprovechada por sectores cristianos que mantienen una actitud -declarada o encubierta- de anticomunismo militante; o por otros más amplios que pretenden canalizar la opción política de los cristianos de una manera exclusiva hacia una línea reformista de tendencia demócrata-cristiana" ( $n .{ }^{\circ} 49$ ). Añadiendo en tono de grave advertencia: "Si la Iglesia institucional pone su aparato eclesial a disposición de un partido político determinado que intente llevar adelante una democracia capitalista interclasista, admitiendo como ineludible el hecho de la existencia de las clases sociales, enfeuda nuevamente su condición profética y degrada con ello el Evangelio" ( $\left(.^{\circ} 50\right)$.

El comunicado de CPS de Catalunya $i$ las Islas Balears, de 30 de enero de 1976, en el comienzo mismo de la transición, afirmaba de forma más rotunda y concreta, más programática, este objetivo político del CPS de abrir el voto y la militancia católica hacia la izquierda: "CPS 
reclama y lucha por el pluralismo de opciones políticas en el seno de la Iglesia, incluída la opción por socialismo de inspiración marxista..." o, en la declaración final de intenciones políticas: “CPS se propone colaborar con todos los esfuerzos que hoy tienen por objeto ayudar a la libre opción de los cristianos para que militen y apoyen a los diversos partidos y organizaciones que luchan por una sociedad socialista, contribuyendo de esta forma al pluralismo político en el seno de la Iglesia".

Este mismo objetivo político concreto e inmediato era formulado por uno de los más cualificados representante de CPS, el jesuíta Juan G. ${ }^{a}$ Nieto, en una conferencia en el centro Loyola de Madrid, el 8 de marzo de 1976: "Uno de los objetivos a corto plazo - afirmaba al final de su conferencia- es llevar a cabo una lucha honesta, pero firme, hasta las últimas consecuencias, por conseguir un pluralismo real dentro de la Iglesia.... Otro objetivo, y no tenemos por qué ocultarlo, es prepararnos para ayudar a sectores cristianos en el momento de las «urnas". Estamos dispuestos a contribuir como, por ejemplo, de forma eficaz lo ha hecho Cps en Italia, a que la correlación de fuerzas resulte efectivamente a favor de los partidos que luchan por el socialismo" ${ }^{30}$

Los mismos comunicados y declaraciones que reclamaban la ampliación del pluralismo político en el interior de la Iglesia, afirmaban la naturaleza no política de lo que incluso preferían llamar "corriente" a "movimiento", $y$, por tanto, el pluralismo de militancias políticas dentro del propio CPS, dentro del abanico socialista. Rechazando tambien, en esta dirección, las acusaciones de constituir un pretendido nuevo integrismo de izquierda.

No es probable que esta declaración de intenciones por parte de CPS fuera factor determinante de la posición neutralista de los obispos, ni causa directa del desbloqueo ideológico que implicó la tasa de voto católico en los partidos de izquierda. Pero en alguna medida debió de influir. En la medida que sólo un análisis concreto y detallado de trayectorias de militantes y grupos cristianos puede aproximadamente definir. $\mathrm{Y}$, en todo caso, las declaraciones de CPS, además de expresar la nueva identidad de un grupo más o menos minoritario e «ilustrado", eran todo un síntoma de ideas que flotaban en el ambiente ${ }^{31}$.

30 Juan N. CARCIA NiETo, "Cristianos por el socialismo en España», conferencia publicada en Fomento Social, 122, 1976, pp.115-125.

31 El análisis de la HOAC, "Ante la actual coyuntura politica", comunicado del Pleno general de representantes, el 21-XII-1975, Boletin HOAC, 679, 15-I-1976 sobre el pluralismo en la Iglesia, era sintomático de la ampliación real y deseable del pluralismo tradicional. Refiriéndose a la postura de la Jerarquía afirmaban: "Admiten un pluralismo político que abarca desde las llamadas "terceras vias" hasta un socialismo moderado, excluyendo de las opciones legítimas a los partidos marxistas-leninistas". 
El diálogo cristiano-marxista y la colaboración en la militancia en los años 60 fue denunciado y rechazado por la mayoría del episcopado, y ha sido considerado como una de las claves de la crisis de la ACE de los años 60 por uno de sus principales protagonistas ${ }^{32}$. Por otra parte, el número de los militantes católicos, en general procedentes de las organizaciones apostólicas de los Movimientos especializados de la AC y de las Congregaciones Marianas, que se integraron o contribuyeron a fundar partidos y sindicatos socialistas, debió ser notable, aunque falten estudios concretos sobre este trasvase ${ }^{33}$.

Desde el punto de vista de la Iglesia y de las organizaciones católicas la identificación más fácil era con el partido socialista y similares ideologías socialistas democráticas. El visceral y tradicional anticomunismo y antimarxismo de los Movimientos apostólicos no afectaba tan directamente a esas organizaciones. El ejemplo más claro sería la escisión del grupo de Izquierda Demócrata Cristiana que se pasó al partido socialista (Peces Barba), o se integró en el PSP de Tierno Galván y en los diferentes partidos de la federación de partidos socialistas.

Cristianos por el socialismo (CPS) surgió sobre todo como un lugar de reflexión y encuentro de militantes cristianos en crisis de identidad, que tras haberse convertido a la militancia socialista o comunista, no querían perder su fe ni su identidad cristiana, pero se veían en la necesidad de reelaborar esa identidad. Según Juan García Nieto, CPS había nacido primero y sobre todo de esta experiencia militante cristiana, estrechamente ligada a la doble crisis de la ACE de 1966-68, más que del diálogo filosófico-teológico cristiano-marxista. Aunque, sin duda, una de las tareas y contribuciones principales de CPS consistió en continuar ese diálogo sobre nuevas bases, en una línea paralela a la nueva «teología de la liberación".

En tanto que lugar de encuentro de militantes cristianos que habian optado por una opción política o sindical socialista y marxista, el proceso de

\footnotetext{
32 J. GuerRa Campos (ed.) Crisis y conflicto en la acción católica española y otros órganos nacionales de apostolado seglar desde 1964, Madrid, 1989, ed. ADUE. Otra interpretación de la crisis en S. Sánchez Terán, "La crisis de la Acción Católica”, en Pablo VI y España, op. cit. pp.8298; en A. Murcia, Obreros y obispos.. op. cit; y en F. Montero, Auge y crisis de la La A.C. especializada, inédito.

${ }_{33}$ Un trabajo pionero en esta línea, el de J. BADA, B. BAYONA Y L. BETES La izquierda ¿de origen cristiano? Zaragoza, 1979, ed. Cometa; Otro más reciente, Joan Costa i Riera, Dels Moviments d'Esglesia a la Militancia Politica, Barcelona, 1997, ed. Mediterránea.
} 
fundación de CPS coincidió y acogió la experiencia de los cristianos en el partido comunista como Comin, que afirmaban la plena compatibilidad y recíproco estímulo de su opción marxista y cristiana. Pero el trasvase o la integración en partidos comunistas fue más tardía, quedó circunscrita a determinados militantes (como Comín, o algunos clérigos), y pasó en general por la previa vinculación a Comisiones Obreras. En la perspectiva de Comín el largo camino de diálogo y colaboración entre el PCE y militantes cristianos, iniciado en torno a 1956, y especialmente potenciado en el contexto del impacto del Vaticano II (1965-67, declaraciones del PCE), había culminado con las declaraciones oficiales del Comité Central, en 1975-76, sobre la total compatibilidad en plano de igualdad, entre la militancia cristiana y la marxista. Frente a las posiciones de otros partidos marxistas-leninistas como el Partido del Trabajo (PT) y la Organización Revolucionaria de Trabajadores (ORT) o el PSOE, que aceptando la colaboración y la participación en la militancia, rechazaban la compatibilidad, tachándola de meramente táctica y oportunista ${ }^{34}$. M. ${ }^{\text {a }}$ Carmen García Nieto ${ }^{35}$ ha señalado los hitos de ese proceso de legitimación de la militancia católica por parte del PCE. Lo que puede resultar paradójico es que mientras el PSOE apenas había elaborado ningun documento, ni había formalizado de ninguna otra forma pública la presencia de militantes católicos en su organización, el partido comunista formuló explícitamente sus nuevas relaciones con los militante católicos.

34 Vid. la posición de Comin en Cristianos en el partido,comunistas en la Iglesia, Laia, Barcelona, 1977: Sobre la evolución de Comín, F.J. Carmona, Cambios en la identidad católica: Juventud de Alfonso Carlos Comin. Madrid, 1995. y algunas declaraciones de los partidos en Mati. as Garcia, Apendice documental sobre "Militancia de los cristianos en partidos eurocomunistas", en Fomento Social, 125, 1977, pp. 73-101. Un análisis del replanteamiento de la cuestión en la crisis del partido comunista italiano en R. Diaz Salazar, Refundación de la izquierda y cristianismo. Las propuestas del PCl. Cuadernos Fe y Secularidad, 12, 1990, y en su libro.

35 En 1956 el informe sobre la Reconciliación Nacional se propone la alianza con los católicos de tendencia democrática; en 1963 Carrillo plantea en el Comité Central "la tesis de la colaboración de los católicos y comunistas, dirigida no sólo a cuestiones tácticas y parciales para conseguir la democracia, sino tambien con vistas a la construcción del socialismo, es decir hacia un acuerdo de objetivos últimos"; en 1973 declaraciones de López Raimundo y de Sanchez Montero, en el Comite central. (este último saluda el nacimiento de CPS); en 1974 ingreso masivo de católicos en el PCE, procedentes muchos de "Bandera Roja", el partido de Comín; en 1975 la declaración programática del comité ejecutivo "Militancia de cristianos en el Partido" marca la inflexión fundamental: reconocimiento de la evolución de la Iglesia; autonomía del debate político; necesidad de superar posturas leninistas; afirmación del caracter laico, no ateo, del PCE; admisión de cristianos con su fe; reconocimiento del potencial revolucionario de la fe. Comín ocupa cargos de máxima responsabilidad en el comite central y el comité ejecutivo del PSUC y del PCE; en 1976 declaraciones programáticas de los comites cetrales del PSUC, del EPK y del PCE de Galicia; y conversaciones de Carrillo y de Comín con un grupo de obispos; en 1979, jornada debate sobre "Cristianismo y socialismo en libertad", organizada por la comisión "Militancia comunista y cristianismo" del PSUC. vid. M. "Carmen Garcia Nieto "Participación en partidos y sindicatos" en Los católicos en la lucha por la democracia, "XX Siglos», 16 (1993), pp. 98-108. 